\title{
Evaluation of Salivary Superoxide Dismutase Levels in Oral Submucous Fibrosis - A Cross Sectional Study
}

\author{
Kavita Nagar, G. P. Sujatha, and Ashok Lingappa
}

\section{ABSTRACT}

Background: Oral Submucous Fibrosis (OSMF) is a potentially malignant disorder with areca nut being the main etiological agent. Increased risk of malignant potential of OSMF necessitates the early diagnosis of the condition. Superoxide dismutase (SOD) scavenges oxygenated free radicals and can be used as a potential biomarker for oral cancer detection.

Objectives: The present study was conducted to estimate and compare salivary SOD levels in patients with OSMF and healthy controls and to compare its levels in different clinical and functional stages of OSMF.

\begin{abstract}
Methodology: The study group (Group 1) included 30 patients of OSMF, and the control group (Group 2) was formed by age and sex-matched healthy individuals. Salivary SOD levels were determined by Nitro Blue Tetrazolium (NBT) chloride method. The levels of salivary SOD were compared between the two groups and the data thus obtained was subjected to statistical analysis using independent sample t-test and one way Analysis of variance (ANOVA) test.

Results: The mean salivary SOD in the study group was $0.583 \mathrm{IU} / \mathrm{mL}$ and $0.864 \mathrm{IU} / \mathrm{mL}$ in control group and the difference was found to be statistically significant. Thus, the patients with OSMF had significantly lower levels of salivary SOD compared to the controls.

Conclusion: The decrease in the salivary SOD levels in patients with OSMF suggests the role of oxidative stress in the pathogenesis of OSMF and initiation and progression of carcinogenesis. Thus, it can be used as a prognostic marker for early detection of carcinoma in patients with OSMF and thereby, improving the quality of life patients.
\end{abstract}

Keywords: Antioxidant, Oral submucous fibrosis, Superoxide dismutase.
Submitted : May 05, 2021

Published : May 27, 2021

ISSN: 2593-8339

DOI: 10.24018 /ejmed.2021.3.3.864

\section{Kavita Nagar*}

e-mail: kavitanagar0789@gmail.com)

G. P. Sujatha

e-mail: sujathashok@gmail.com)

Ashok Lingappa

e-mail: ashokl_2002@yahoo.co.in)

*Corresponding Author

\section{INTRODUCTION}

According to the traditional ayurvedic medicine, chewing areca nut and betel leaf is a good remedy against halitosis. It has stimulating effect on central nervous system and saliva, deworming and digestive properties. Along with these beneficial effects of areca nut one of its most harmful effects is the development of potentially malignant disorder called Oral Submucous Fibrosis (OSMF) [1].

OSMF is a chronic disorder characterized by progressive fibrosis of oral cavity and upper digestive tract, resulting in reduced mouth opening, intolerance to spicy food, restricted tongue movements and difficulty in swallowing and phonation. Progressive restricted mouth opening leads to inability to take proper meals and poor oral hygiene which can affect the quality of life. The most widely accepted definition of the disease is the one given by Pindborg and Sirsat in 1966 [2]. Formerly confined to the Indian subcontinent, it is now often seen in the Asian populations of the United Kingdom, United States of America, and other developed countries, and is therefore a serious problem for global health [3]. The prevalence rate in India is about $0.2-$ $0.5 \%$ and prevalence by gender varying from $0.2 \%$ to $2.3 \%$ in males and $1.2 \%$ to $4.57 \%$ in females [4].
The pathogenesis of the disease is believed to be multifactorial including areca nut chewing, ingestion of chilies, genetic and immunologic processes, nutritional deficiencies. The association of the habit of consuming betel nut (areca catechu) has now been widely recognized as causative. In 2004, the second IARC (International Agency for Research on Cancer) declared areca-nut and betel-quid (with or without tobacco) as a 'group one carcinogen' [5].

Paymaster was first to observe the onset of slow-growing oral squamous cell carcinoma (OSCC) among OSMF patients and described its possible precancerous nature [6]. Later, Pindborg substantiated the malignant potential of OSMF using certain criteria [7]. The incidence of dysplasia in OSMF varies from 7 to $26 \%$. In a long-term follow-up study over a period of 17 years by Murti et al., the annual malignant transformation rate was approximately $0.5 \%$ or $7.6 \%$ over 17 years [8].

There is a wealth of scientifically sound evidence on the various aspects of OSMF malignant transformation with reactive oxygen species (ROS) playing a significant role in this process. ROS induced DNA damage occurs as the result of chemical attack originating from arecoline, the most abundant areca alkaloid. 
The scavenging of the ROS is done by enzymatic and nonenzymatic antioxidants. The enzymatic antioxidant includes superoxide dismutase (SOD), catalase, glutathione peroxidase [9]. SOD, first discovered by Mc Cord and Fridovich, is an intracellular enzyme, which, along with other members of the antioxidant system, scavenges oxygenated free radicals such as the superoxide anion or the hydroxyl radical. Thus, it is an oxidative stress related molecule which can be used as a potential biomarker for oral cancer detection [10]. Early diagnosis of cancerous condition would result in better prognosis. It is possible even at premalignant stage by use of saliva for detection of superoxide dismutase levels. The levels of salivary SOD are decreased in oral leukoplakia and oral cancer patients when compared to healthy controls and this suggests that salivary SOD levels could be a useful biomarker in oral carcinogenesis [11].

Hence, the objective of this study is to evaluate the levels of salivary SOD in OSMF patients as compared to healthy subjects and among the different stages of the disease progression, so that early detection of cancerous state can be done and appropriate measures can be taken to reduce the morbidity related to it.

\section{Methodology}

This cross-sectional study consisted of two groups. Group 1 was formed by the patients clinically diagnosed and histopathologically confirmed as OSMF with age range of 20 to 50 years and oral hygiene index score $<3$ or $=3$. Group 2 was formed by age and sex matched healthy individuals with OHI score <3. The subjects were outpatients in the Department of Oral Medicine and Radiology, Bapuji Dental College and Hospital, Davangere, over a period of 10 months (September 2017 - June 2018). Subjects with known systemic diseases and previous history of OSMF treatment were excluded. The sample size was 60 with 30 subjects in each group, determined by using the sample size formula after considering the prevalence of the disease and patients of the hospital.

Ethical clearance was obtained from the Institutional Review Board for conducting the study. After clinical examination, the written consent was taken from the subject prior to carrying out the study. Diagnosis of OSMF was given based on the clinical features along with the clinical and functional staging (Fig. 1) according to the classification by Chandramani More et al [4]. After routine blood investigations, incisional biopsy was carried out to determine histopathological staging according to Pindborg JJ and Sirsat [2].

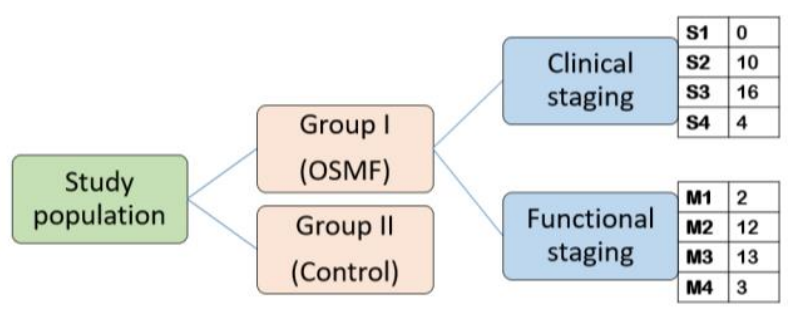

Fig. 1. Flowchart showing groups and subgroups of the study population.
For saliva sample collection, the subjects were asked to refrain from eating, drinking, or oral hygiene procedures for at least $1 \mathrm{~h}$ prior to the collection time (preferred early morning 8-10 am). The subjects were asked to rinse mouth with distilled water for 1 minute. Five minutes after this oral rinse, the subjects were asked to spit into sterile plastic container with wide mouth till $2 \mathrm{~mL}$ of saliva was collected. The samples were stored at temperature of $4{ }^{\circ} \mathrm{C}$ immediately and send to laboratory for processing within 1 hour.

Salivary SOD levels were determined by Nitro Blue Tetrazolium (NBT) chloride method given by Beauchamp and Fridovich [12]. Salivary samples were centrifuged at $10,000 \mathrm{rpm}$ for $15 \mathrm{~min}$. The supernatant was used for the assay. For each sample analyzed a corresponding control was maintained. The beakers were marked as TEST, STANDARD and CONTROL and were subjected to illumination for $10 \mathrm{~min}$ in an illumination chamber lined with aluminium foil and fitted with a $15 \mathrm{~W}$ fluorescent lamp. Following illumination, immediately the optical density of all the reaction mixtures were read at $560 \mathrm{~nm}$; units of enzyme present in the sample was calculated using the formula and expressed as IU/mg protein. SOD activity is measured in terms of its ability to inhibit the reduction of NBT due to $\mathrm{O}^{2-}$. A unit of SOD is defined as the amount causing $50 \%$ of the maximum inhibition of NBT reduction.

Independent sample t-test and one way Analysis of variance (ANOVA) test was used to compare the levels of SOD in OSMF and healthy controls and among different grades of OSMF.

\section{RESULTS}

The salivary SOD in the study group ranged from 0.324 to $0.852 \mathrm{IU} / \mathrm{mL}$ with a mean value of $0.583 \mathrm{IU} / \mathrm{mL}$. In the control group the SOD levels ranged from 0.984 to 0.758 $\mathrm{IU} / \mathrm{mL}$ with a mean of $0.864 \mathrm{IU} / \mathrm{mL}$ (Fig. 2, Table I). The difference in the mean of salivary SOD levels was found to be statistically significant with $\mathrm{p}$ value of $<0.001$.

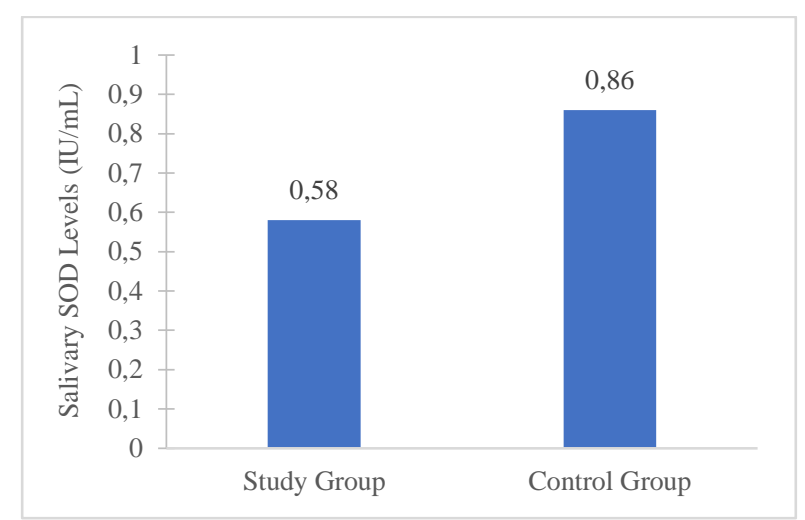

Fig. 2. Graph showing comparison of mean salivary SOD between study and control group.

TABLE I: COMPARISON OF MEAN SALIVARY SOD BETWEEN STUDY AND CONTROL GROUP

\begin{tabular}{ccccccc}
\hline \multicolumn{7}{c}{ CONTROL GROUP } \\
Groups & $\mathrm{N}$ & $\begin{array}{c}\text { Mean } \\
(\mathrm{SD})\end{array}$ & $\begin{array}{c}\text { Mean } \\
\text { difference } \\
(95 \% \mathrm{CI})\end{array}$ & $\mathrm{t}$ & $\mathrm{df}$ & $\mathrm{p}$-value \\
\hline Study & 30 & $\begin{array}{c}0.58 \\
(0.13)\end{array}$ & $\begin{array}{c}-0.28 \\
(-0.34,\end{array}$ \\
Control & 30 & $\begin{array}{c}0.86 \\
(0.07)\end{array}$ & $-0.23)$ & -10.291 & 58 & $<0.001^{*}$ \\
\hline *p<0.05 statistically significant. & & & & \\
\hline
\end{tabular}


When the salivary SOD levels were compared with the clinical (Fig. 3, Table II) and functional staging (Fig. 4, Table III), statistically significant $(\mathrm{p}<0.001)$ was found among the subgroups.

It was noted that as the stages of OSMF progressed, there was decrease in the mean salivary SOD level.

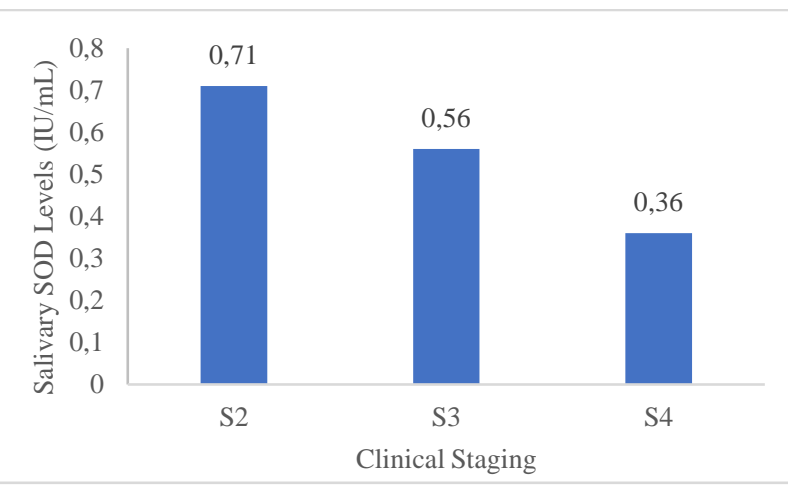

Fig. 3. Graph showing comparison of salivary SOD levels with clinical staging.

TABLE II: COMPARISON OF SALIVARY SOD LEVELS WITH CLINICAL STAGING

(a)

\begin{tabular}{|c|c|c|c|c|c|c|}
\hline $\begin{array}{l}\text { Clinical } \\
\text { staging }\end{array}$ & 1 & Mean & SD & \multicolumn{3}{|c|}{ ANOVA } \\
\hline S2 & 10 & 0.71 & 0.09 & $\mathrm{~F}$ & \multicolumn{2}{|c|}{$\mathrm{p}$-value } \\
\hline $\begin{array}{l}\text { S3 } \\
\text { S4 }\end{array}$ & 1 & $\begin{array}{l}0.56 \\
0.36\end{array}$ & $\begin{array}{l}0.06 \\
0.03\end{array}$ & 37.80 & \multicolumn{2}{|c|}{$<0.001 *$} \\
\hline \multicolumn{7}{|l|}{ (b) } \\
\hline \multirow{2}{*}{$\begin{array}{l}\text { Clinical } \\
\text { stage } \\
\text { (I) }\end{array}$} & \multirow{2}{*}{$\begin{array}{c}\text { Clinical } \\
\text { stage } \\
(\mathrm{J})\end{array}$} & \multirow{2}{*}{$\begin{array}{c}\text { Mean } \\
\text { difference } \\
(\mathrm{I}-\mathrm{J}) \\
\end{array}$} & \multirow{2}{*}{$\begin{array}{l}\text { Standard } \\
\text { error }\end{array}$} & \multirow[b]{2}{*}{$\mathrm{p}$-value } & \multicolumn{2}{|c|}{$95 \% \mathrm{CI}$} \\
\hline & & & & & $\begin{array}{l}\text { Lower } \\
\text { bound }\end{array}$ & $\begin{array}{l}\text { Upper } \\
\text { bound }\end{array}$ \\
\hline \multirow{2}{*}{ S2 } & S3 & 0.15 & 0.03 & $<0.001 *$ & 0.08 & 0.22 \\
\hline & S4 & 0.35 & 0.04 & $<0.001 *$ & 0.25 & 0.46 \\
\hline S3 & S4 & 0.21 & 0.04 & $<0.001 *$ & 0.11 & 0.30 \\
\hline
\end{tabular}

$* \mathrm{p}<0.05$ statistically significant.

TABLE III: COMPARISON OF SALIVARY SOD LEVELS WITH FUNCTIONAL STAGING

\begin{tabular}{cccccc}
\hline $\begin{array}{c}\text { Functional } \\
\text { staging }\end{array}$ & $\mathrm{N}$ & Mean & $\mathrm{SD}$ & \multicolumn{2}{c}{ ANOVA } \\
\hline M1 & 2 & 0.80 & 0.02 & $\mathrm{~F}$ & $\mathrm{p}$-value \\
M2 & 12 & 0.64 & 0.12 & & \\
M3 & 13 & 0.55 & 0.07 & 9.138 & $<0.001^{*}$ \\
M4 & 3 & 0.39 & 0.08 & & \\
\hline
\end{tabular}

\begin{tabular}{|c|c|c|c|c|c|c|}
\hline \multicolumn{7}{|l|}{ (b) } \\
\hline \multirow{2}{*}{$\begin{array}{l}\text { Functional } \\
\text { stage (I) }\end{array}$} & \multirow{2}{*}{$\begin{array}{l}\text { Functional } \\
\text { stage }(\mathrm{J})\end{array}$} & \multirow{2}{*}{$\begin{array}{c}\text { Mean } \\
\text { difference } \\
(\mathrm{I}-\mathrm{J})\end{array}$} & \multirow{2}{*}{$\begin{array}{l}\text { Standard } \\
\text { error }\end{array}$} & \multirow[b]{2}{*}{$\begin{array}{c}\mathrm{p}- \\
\text { value }\end{array}$} & \multicolumn{2}{|c|}{$95 \%$ CI } \\
\hline & & & & & $\begin{array}{l}\text { Lower } \\
\text { bound }\end{array}$ & $\begin{array}{l}\text { Upper } \\
\text { bound }\end{array}$ \\
\hline \multirow{3}{*}{ M1 } & M2 & 0.16 & 0.07 & 0.17 & -0.05 & 0.36 \\
\hline & M3 & 0.25 & 0.07 & $0.01 *$ & 0.05 & 0.45 \\
\hline & M4 & 0.41 & 0.09 & $0.001 *$ & 0.17 & 0.65 \\
\hline \multirow{2}{*}{ M2 } & M3 & 0.09 & 0.04 & 0.11 & -0.02 & 0.20 \\
\hline & M4 & 0.25 & 0.06 & $0.003 *$ & 0.08 & 0.42 \\
\hline M3 & M4 & 0.16 & 0.06 & 0.07 & -0.01 & 0.33 \\
\hline
\end{tabular}

$* \mathrm{p}<0.05$ statistically significant.

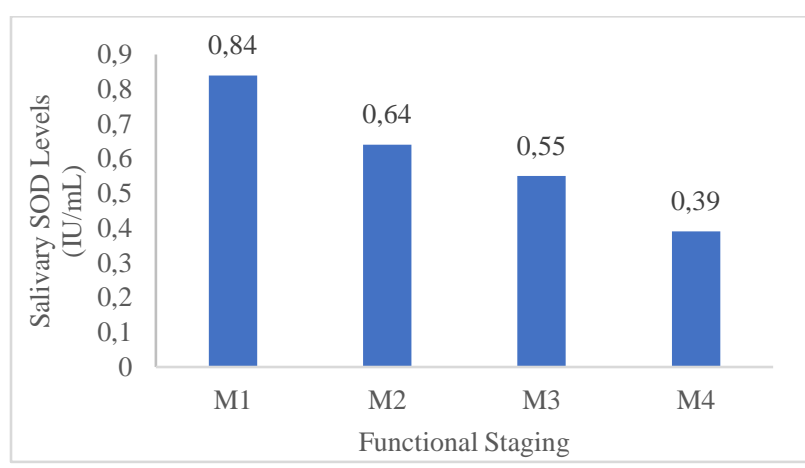

Fig. 4. Graph showing comparison of salivary SOD levels with functional staging.

\section{DISCUSSION}

OSCC is one of the most common cancers in the world, often preceded by specific pre-malignant lesions or conditions, the most common amongst them are the oral leukoplakia and oral submucous fibrosis.

Oxidative stress has emerged as one of the leading causes of cancer. In patients having tobacco, betel quid, and other addictive habits, the equilibrium between oxidative stress and the antioxidant enzyme is adversely affected. A close inter-networking between genetic susceptibility, tobacco usage, and oxidative stress can synergistically induce carcinogenesis in such patients [13].

Antioxidant enzymes such as SOD protect the cells against ROS. Enzymatic antioxidant SOD plays a key role in detoxification of superoxide anion radical and hence diminishes the toxic effects of this radical and other free radicals such as hydrogen peroxide and hydroxyl radical from secondary reactions. Excessive production of ROS or deficient antioxidant system may also lead to malignant transformation. Thus, the serum SOD can act as a prognostic and therapeutic biomarker in oral premalignancy and malignancy.

Although many studies have been conducted to estimate the serum levels of SOD, but only a few studies have evaluated the salivary levels of SOD. Due to the paucity of such studies in literature, there are no well-established normal levels of salivary SOD.

Early detection of OSCC is a key factor in improving the prognosis and survival rate of the patient. Rapid advancement in the field of diagnosis has enabled early diagnosis of many potentially malignant conditions even before its clinical manifestations. One such diagnostic modality that has gained much relevance in the field of molecular biology has been the discovery of salivary biomarkers. Salivary biomarkers have many advantages over serum because they are inexpensive, non-invasive, costeffective and easily accessible media. Thus, the use of saliva as a diagnostic medium lacks the drama of blood, the sincerity of sweat and emotional appeal of tears [14].

In literature, there is no study evaluating the levels of SOD -in the saliva of patients with OSMF. Thus, the present study is the first to evaluate levels of salivary SOD in OSMF patients. However, serum SOD levels have been determined by various studies. Salivary SOD has been estimated in other potentially malignant disorders such as oral leukoplakia.

The patients with OSMF had significantly (p-value $<0.001)$ lower levels of salivary SOD compared to the controls. These results were in accordance with the results of a study conducted by Shetty SR et al [11] where statistically significant difference was observed between the levels of salivary SOD in between oral cancer, oral leukoplakia groups when compared to healthy controls. In study by Metkari S. et al [15] a statistically significant decreased levels of serum SOD were found among OSF group as compared to control group. The mean SOD level gradually decreased in relation with clinical grades of OSMF from early to advanced grades. Another study with similar results was conducted by Gurudath et al [16], where the mean serum SOD level in OSF group was significantly decreased as compared to the control group. Also, the study conducted by Bale R. et al [17] showed consistent results. Comparison of SOD levels 
between healthy volunteers and OSMF participants was statistically significant. It was also reported that as the clinical stages of OSMF increased, the mean serum SOD level decreased. Similar results were observed in the study conducted by Sadaksharam J [18]. Thus, the level of SOD was decreased in OSMF patients when compared to the healthy controls. However, there were no studies comparing the levels of SOD with the functional stages of OSMF.

The analysis of the results of the present study suggests that the levels of the antioxidant enzyme SOD are decreased in OSMF and as the disease progresses, there is a further reduction in the levels of this enzyme. Thus, this antioxidant enzyme might serve as a guide for prognosis in patients suffering from such a malady. There were several limitations in the study, first being small sample size. Study sample represented regional population. Another limitation was that there were unequal number of subjects in the subgroups. This can be attributed to the fact that majority of patients do not report to the clinic at initial stages of the disease. Therefore, further elaborate studies with a larger sample size of OSMF in different regions are needed to ascertain the inhibitory role of this antioxidant enzyme in the initiation and promotion of carcinogenesis.

\section{CONCLUSION}

The decrease in the salivary SOD levels in patients with OSMF suggests the role of oxidative stress in pathogenesis of OSMF and initiation and progression of carcinogenesis. Thus, it can be used as prognostic marker for early detection of carcinoma in patients with potentially malignant disorders such as OSMF and thereby, improving the quality of life of patients.

\section{ACKNOWLEDGMENT}

We acknowledge the kind help and support from the department of Oral Pathology and Biochemistry in the completion of this study.

\section{REFERENCES}

[1] Prabhu RV, Prabhu V, Chatra L, Shenai P, Suvarna N, Dandekeri S Areca nut and its role in oral submucous fibrosis. Journal of Clinical and Experimental Dentistry. 2014;6(5):e569-e575.

[2] Pindborg JJ, Sirsat SM. Oral submucous fibrosis. Oral Surg Oral Med Oral Pathol. 1966;22:764-79.

[3] Arakeri G, Brennan PA. Oral submucous fibrosis: an overview of the aetiology, pathogenesis, classification, and principles of management. Br J Oral Maxillofac Surg. 2013 Oct;51(7):587-93.

[4] More CB, Das S, Patel H, Adalja C, Kamatchi V, Venkatesh R. Proposed clinical classification for oral submucous fibrosis. Oral Oncol. 2012;48(3):200-2.

[5] IARC Working Group on the Evaluation of Carcinogenic Risks to Humans, World Health Organization, International Agency for Research on Cancer. Betel-quid and areca-nut chewing and some areca-nut-derived nitrosamines. 2004.

[6] Paymaster JC. Cancer of the buccal mucosa; a clinical study of 650 casesin Indian patients. Cancer 1956;9:431-5.

[7] Pindborg JJ, Murti PR, Bhonsle RB, Gupta PC, Daftary DK, Metha F. Oral submucous fibrosis as a precancerous condition. Scand J Dent Res 1984;92:224-9.

[8] Murti PR, Bhonsle RB, Pindborg JJ, Daftary DK, Gupta PC, Mehta FS. Malignant transformation rate in oral submucous fibrosis over a 17 -year period. Community Dent Oral Epidemiol. 1985 Dec;13(6):340-1.
[9] Bathi RJ, Rao R, Mutalik S. GST null phenotype and antioxidants; risk indicators for oral precancer and cancer. Indian $J$ Dent Res 2009;20:298-302.

[10] Michelson AM. Toxicity of superoxide radical anions. In: Michelson AM, McCord JM, Fridovich. Superoxide and Superoxide Dismutase $1^{\text {st }}$ ed. London, UK: Academic Press; 1977.

[11] Shetty SR, Babu SG, Kumari S, Karikal A, Shetty P, Hegde S. Salivary superoxide dismutase levels in oral leukoplakia and oral squamous cel carcinoma; a clinicopathological study. Oxid Antioxid Med Sci. 2013;2(1):69-71.

[12] Beauchamp C, Fridovich I. Superoxide dismutase: improved assays and an assay applicable to acrylamide gels. Anal Biochem. 1971;44(1):276-87.

[13] Patel BP, Rawal UM, Rawal RM, Shukla SN, Patel PS. Tobacco, antioxidant enzymes, oxidative stress, and genetic susceptibility in oral cancer. Am J Clin Oncol. 2008 Oct;31(5):454-9.

[14] Madalli VB, Basavaraddi SM, Burde K, Horatti P. Saliva-A diagnostic tool. IOSR J Dent Med Sci. 2013 Nov; 11:96-99.

[15] Metkari SB, Tupkari J V, Barpande S R. An estimation of serum malondialdehyde, superoxide dismutase and vitamin $\mathrm{A}$ in oral submucous fibrosis and its clinicopathologic correlation. J Oral Maxillofac Pathol 2007;11:23-7.

[16] Gurudath S, Naik RM, Ganapathy K S, Guruprasad Y, Sujatha D, Pai A. Superoxide dismutase and glutathione peroxidase in oral submucous fibrosis, oral leukoplakia, and oral cancer: A comparative study. J Orofac Sci 2012;4:114-9.

[17] Bale R, Kattappagari KK, Vidya D, Vuddandi S, Gummalla C, Baddam VR. Oral submucous fibrosis: A quantitative assessment of serum malondialdehyde, superoxide dismutase and correlation with clinical staging. J Oral Maxillofac Pathol 2017;21:41-5.

[18] Sadaksharam J. Significance of Serum Nitric Oxide and Superoxide Dismutase in Oral Submucous Fibrosis and Squamous Cell Carcinoma: A Comparative Study. Contemporary Clinical Dentistry. 2018;9(2):283-288.

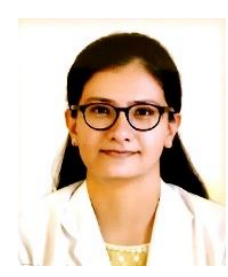

Dr. Kavita Nagar is postgraduate student Department of Oral Medicine and Radiology, Bapuj Dental College and Hospital, Davangere, Karnataka.

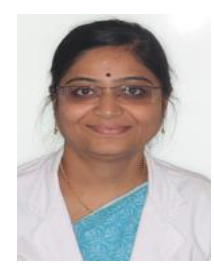

Dr. Sujatha G.P. is Professor, Department of Oral Medicine and Radiology, Bapuji Dental College and Hospital, Davangere, Karnataka. She specializes in red and white lesions. She has many international and national publications to her credit.

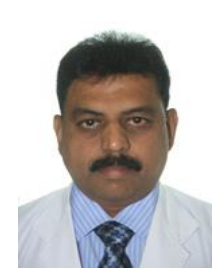

Dr. Ashok Lingappa is Professor and Head of Department, Department of Oral Medicine and Radiology, Bapuji Dental College and Hospital, Davangere, Karnataka. He specializes in potentially malignant disorders and orofacial pain. Recognized Ph.D. guide in dental faculty RGUHS, Bangalore. He has 15 international and 70 national publications to his name. 